\title{
L'Aliénation culturelle en Afrique à travers le théâtre africain
}

\author{
Ben Jukpor \\ Brandon University (Manitoba)
}

\section{Introduction}

Le terme aliénation recouvre des idées diverses et jouit par là d'un champ sémantique très étendu. Si l'on se réfère à l'étymologie du mot, le terme latin alienatio exprime déjà trois concepts distincts. Dans le domaine juridique, il désigne le transfert de propriété. Dans le domaine proprement social, il désigne la désaffection (disiunctio, aversatio) qui se substitue à l'attachement qu'on éprouvait pour quelqu'un ou pour quelque chose. En médecine, il signifie la démence (dementia, insania). ${ }^{1}$ On retrouve pourtant une idée maîtresse qui relie ces trois acceptions du terme: idée de séparation ou de passage d'un état initial à un nouvel état. Ce nouvel état représente une "déformation" de l'état initial et par conséquent est souvent peu souhaitable. ${ }^{2}$

C'est aussi cette idée maîtresse de séparation qu'on retrouve chez les critiques qui ont étudié le concept d'aliénation, bien que cette idée de séparation ne soit pas toujours très clairement explicitée. Ainsi Richard Schacht écrit que l'emploi le plus commun du terme aliénation en sociologie exprime la séparation de l'individu de certains aspects de la vie socio-culturelle de sa société. ${ }^{3}$ Autrement dit l'individu se tient à l'écart et rejette certains aspects culturels de sa société. Bernard Murchland fait remarquer qu'il y a dans toute forme d'aliénation un élément de désunion ou de séparation. ${ }^{4}$ Aimé Césaire qui évoque l'aliénation du nègre à la suite du baptême colonial, parle du nègre qui est devenu "chaque jour plus bas, plus lâche, [...] plus séparé de soi-même."5

L'idée de séparation que recouvre le concept d'aliénation prend chez Karl Marx un aspect presque pathologique où l'aliénation exprime le rapport faux ou dénaturé entre 
l'homme, son travail et le produit de ce travail. Loin de dominer son travail et le produit du travail, 1'homme est dominé par l'un et par l'autre. ${ }^{6}$ Le rapport dénaturé entre l'homme et son travail existe aussi, pour Karl Marx entre l'homme aliéné et sa société. L'aliéné se tient à l'écart des valeurs culturelles de sa société. Ses valeurs de référence viennent d'ailleurs. Cette forme d'aliénation marxiste évoque dans une certaine mesure le sens métaphorique du terme chez André Lalande où le terme exprime 1" "état de celui qui appartient à un autre." 7 Autrement dit, l'aliéné social a tendance à rejeter ses propres valeurs socio-culturelles au profit des valeurs de référence qui appartiennent à une autre culture. Il y a ainsi séparation entre ce que l'homme est, et devrait être, et ce qu'il veut être.

Cette idée d'appartenance à un autre rejoint en quelque sorte le sens extensif d'aliénation tel que le présente Paul Robert, qui note que c'est le sens courant au milieu $\mathrm{du} \mathrm{XX} \mathrm{X}^{\mathrm{e}}$ siècle, et particulièrement à la mode chez certains intellectuels. Ici, dans son sens extensif, le terme d'aliénation désigne:

Tout processus par lequel l'être humain est rendu comme étranger à luimême et perd la conscience claire de ses rapports avec l'Autre.

En Afrique, l'aliénation, du moins l'aliénation socio-culturelle, se présente surtout suivant le sens exprimé par André Lalande et Paul Robert. Les aliénés sociaux en Afrique rejettent la culture africaine, leur propre culture, au profit de la culture occidentale introduite en Afrique par le fait colonial. Le colonialisme a tôt fait de séduire et de convaincre certains Africains que la culture africaine relève de la barbarie. Pour ces Africains, la vraie valeur de l'être humain se mesure désormais par le fait de son occidentalisation, c'est-à-dire par le fait de sa séparation de ses propres valeurs culturelles, ou plus exactement par le fait de son aliénation. C'est dire que l'aliénation culturelle en Afrique est souvent consciente. Elle est souvent volontairement choisie par l'aliéné comme une manière de se donner de l'importance. Puisque la culture africaine lui apparaît inférieure à la culture occidentale, son choix de cette dernière aurait le mérite d'augmenter sa valeur humaine, c'est-à-dire d'affirmer sa supériorité face aux autres Africains qui se tiennent toujours aux valeurs traditionnelles de l'Afrique.

Mais l'aliénation culturelle en Afrique peut être inconsciente aussi. Lorsqu'elle est inconsciente, l'aliéné social agit pour profiter des avantages qu'il croit que la culture occidentale favorise. Mais il ne se rend pas toujours compte qu'il ne peut profiter de ces avantages qu'au détriment de sa propre culture. Alors que dans l'aliénation con- 
sciente 1'aliéné fait clairement fi de ses valeurs culturelles, dans l'aliénation inconsciente l'aliéné aspire à des valeurs de référence occidentales sans pourtant oublier complètement ses propres valeurs culturelles. En fait il tente vaguement de conjuguer les premières avec les dernières. Mais tentative vaine car il ne manque pas de noter, sans cesse, et de souligner les avantages envoûtants de la culture occidentale.

Notre étude de l'aliénation culturelle en Afrique, à travers le théâtre africain, se portera donc sur ces deux formes d'aliénation: l'aliénation consciente et l'aliénation inconsciente. Les deux formes d'aliénation ont leurs racines dans le fait colonial.

\section{Aliénation consciente}

Ce qui caractérise cette forme d'aliénation en Afrique, c'est le rejet volontaire par l'aliéné des valeurs culturelles de l'Afrique et le désir acharné de remplacer la culture africaine par les valeurs de référence occidentales. Pour l'aliéné, la culture africaine est dégradante et infériorisante. Or le personnage a déjà conscience de sa supériorité aux autres Africains, et la manière de confirmer cette supériorité consiste à s'occidentaliser, à se rendre comme "étranger à lui-même." Il renonce donc à sa culture pour mieux vivre l'idée qu'il se fait de lui-même.

C'est essentiellement la situation que Bernard Dadié dépeint dans Monsieur Thôgô-gnini et John Pliya dans La Secrétaire particulière, les deux pièces qui font l'objet de notre étude dans l'aliénation consciente.

Dans Monsieur Thôgô-gnini Bernard Dadié décrit la rencontre entre deux cultures - la culture africaine et la culture européenne - et met en relief surtout le résultat de cette rencontre qui s'exprime largement par l'aliénation culturelle du pays africain. Le dramaturge ne situe pas clairement le pays africain en question. On sait seulement qu'il s'agit d'un pays de l'Afrique de l'Ouest. Le pays européen n'est pas bien situé non plus. On parle simplement des Blancs venus d'Europe. Si le dramaturge ne précise pas les pays en question, c'est peut-être parce qu'il veut donner l'impression que la rencontre entre l'Afrique et l'Europe produit toujours le même résultat: l'aliénation culturelle de la première, quels que soient les pays concernés dans la rencontre, et quel que soit le but proféré par l'Europe en établissant un contact avec l'Afrique.

Ainsi les Blancs qui arrivent en Afrique au commencement de la pièce font entendre qu'ils sont venus en mission d'amitié et qu'ils désirent établir des liens de commerce entre les deux pays. Puisque l'objet important de la mission est le commerce, 
le délégué principal d'Europe, nommé simplement Le Blanc, ne tarde pas à sensibiliser les Noirs au culte de l'argent, voie fondamentale de commerce en Europe. Il décrit l'argent comme le seul dieu que l'Europe reconnaît, "un dieu visible, tangible" (I, p. 18). La foule est éblouie, et Monsieur Thôgô-gnini qui avait vécu en Occident, et qui n'ignore pas l'importance d'une économie monétaire, est encore plus séduit que les autres et réclame l'argent que Le Blanc tient devant la foule comme une sorte de baguette magique qui exorcise un démon: "De l'argent! De l'argent! Donne-le-moi" (I, p. 18). Mais l'argent, on ne le donne pas comme cela. On le mérite, on le gagne. Et profitant de l'éblouissement collectif des Noirs, Le Blanc précise en refusant la demande de Monsieur Thôgô-gnini:

Non! Il faut le gagner, en travaillant. Il faudra planter beaucoup de palmiers; beaucoup d'arachides. L'Europe en a besoin. Enrichissezvous (I, pp. 18-19).

Cette invitation à s'enrichir a du sens surtout pour les gens comme Monsieur Thôgô-gnini qui sont en mesure de pouvoir profiter de la situation. Ces gens ont des palmiers qu'ils peuvent exploiter pour s'enrichir. D'ailleurs, Monsieur Thôgô-gnini n'est pas un personnage quelconque. Il est le porte-canne du roi, c'est-à-dire l'équivalent du premier ministre en Afrique contemporaine. Il est, par conséquent, haut placé dans la société. Il décide donc de profiter de la recommandation du Blanc, d'autant plus que sa position sociale rend assez facile l'acquisition de l'argent.

Mais cette acquisition de l'argent, comme Bernard Dadié semble le suggérer, ne saurait se réaliser qu'au prix de la perte d'identité, c'est-à-dire au prix de l'aliénation culturelle. C'est ainsi que Monsieur Thôgô-gnini qui, au premier tableau, lors de la rencontre avec Le Blanc, est en tenue nationale, apparaît au commencement du deuxième tableau "habillé en occidental" (II, p. 21). En fait, d'ici jusqu'à la fin de la pièce, Monsieur Thôgô-gnini ne revient plus à la tenue nationale.

En plus il se laisse finalement "acheter" par les Blancs qui lui remettent une somme d'argent, le nomment leur "auxiliaire le plus précieux" (II, p. 22) dans l'exploitation du pays, et lui promettent encore beaucoup d'argent et beaucoup d'honneurs. Dorénavant, Monsieur Thôgô-gnini poussera les autres Noirs à travailler avec acharnement dans la palmeraie, au profit des Blancs et de lui-même. L'idée d'avoir de l'argent et d'en avoir beaucoup devient presque obsessionnelle chez lui et l'expression "De l'argent! De l'argent! Beaucoup d'honneurs... Vite! Vite!" (II, p. 23), lui échappe sans cesse comme s'il s'agissait d'une sorte de formule d'incantation. 
Monsieur Thôgô-gnini se rend compte aussi que pour avoir beaucoup d'argent il ne faut plus mener la vie traditionnelle, une vie collectiviste qui caractérise l'Afrique d'avant la colonisation. Tout le monde ne doit plus s'occuper de tout le monde. C'est désormais "chacun pour soi" (III, p. 27). Monsieur Thôgô-gnini rejette ainsi ce qui constitue l'élément fondamental de la culture africaine au profit d'une conception de vie étrangère à l'Afrique. Or la nouvelle philosophie de vie thôgô-gninienne implique essentiellement l'exploitation des uns par les autres, des faibles par les forts, ou plus exactement des pauvres par les riches. Cette nouvelle forme de vie, par rapport à la vie traditionnelle, est une vie d'enfer. Monsieur Thôgô-gnini en est bien conscient, mais il en est bien content aussi car étant devenu très riche et puissant, il détient l'autorité sur tous ces compatriotes. Il s'en enorgueillit devant son ami, Fakron:

[...]Moi, Thôgô-gnini, je ne suis peut-être pas aimé, mais je suis craint, respecté. Eh oui, je puis impunément faire ce qui me plaît [...] Eh oui, mon ami, c'est ainsi que devient la belle vie d'hier, une vie d'enfer...dans une vie d'enfer, on se fait diable (IV, pp. 39-40).

Affirmant que les Africains doivent maintenant choisir entre ce qui était hier et ce qui sera demain, il se déclare comme étant "l'image de demain... Un demain impitoyable" (Ibid., p. 40).

Ce demain impitoyable que Monsieur Thôgô-gnini représente appartient à ce que le boy de café décrit comme "une classe de blancs noirs" (Ibid., p. 41). Le boy de café précise:

[...]Cette classe est impatiente, avide, brutale... Ah si les vieux nègres pouvaient sortir de leurs tombeaux, ils ne nous reconnaitraient plus et se demanderaient si les noirs ne sont pas en train de perdre leur couleur noire, et leur rire aussi (IV, p. 42).

Fakron, l'ami de Thôgô-gnini, reprend l'idée du boy de café et ajoute:

Les rois d'Europe recherchaient le Noir pour apprendre à rire. Aujourd'hui, le Noir abandonne le rire... Demain, il nous faudra payer des Blancs pour réapprendre à rire (Ibid.). 
Le mot "rire" ne doit pas être pris ici seulement au sens littéral. Il renvoie aussi au sens figuré où il désigne la situation de joie qui caractérise l'existence collectiviste de l'Afrique d'avant la colonisation où l'homme n'était jamais seul dans l'état de bonheur comme dans celui de malheur. Il s'agit d'une existence communautaire où tout se partage, ce qui rend les épreuves de la vie beaucoup plus supportables. Cette forme de vie n'est plus possible dans l'Afrique des Thôgô-gnini. Pour Monsieur Thôgôgnini, tout le pays se résume en sa personne. Il croit que tout lui appartient et doit lui appartenir. Il transforme ses compatriotes en vraies victimes. Il leur "achète" des fûts d'huile de palme qui ne sont jamais payés. Mais il règle promptement ses comptes avec ses amis blancs. Ceux-ci se moquent d'ailleurs de lui au fur et à mesure qu'il piétine la culture africaine. C'est ainsi qu'il se pavane dans son complet en jute qu'ils lui donnent en lui disant que c'est

Le plus beau tissu qui se fait actuellement en Europe; le tissu que portent les hommes en vue. Un tissu exclusif (V, p. 63).

Il renonce à la religion traditionnelle et veut convertir son père, rétroactivement, en demandant aux Blancs de faire dire une messe en Europe à la mémoire de son père mort il y a des années en Afrique. Les Blancs s'étonnent de la stupidité du personnage, mais ils se donnent aussi du bon temps aux dépens de toute l'Afrique. Ils l'invitent à européaniser son nom qu'ils trouvent banal. Et Monsieur Thôgô-gnini prend le nom

"Monsieur de Thôgô-gnini de la Panthère des Afriques des Trafics du Bénin" (V, p. 71).

Par cette dénaturation de son nom, par sa tenue de jute qui constitue une insulte flagrante au personnage, bien qu'il ne s'en rende pas compte, Monsieur Thôgô-gnini, tout à fait aliéné, apparaît comme une sorte de bête amusante. Albert Memmi qui a bien étudié cette perte d'identité de l'homme noir écrit:

Pire que la destruction physique, les coups, l'exclusion professionnelle, pire que la mort même, est cette destruction intérieure, cet avilissement consentant de l'homme noir. Car il finit par accepter ce que lui raconte l'homme blanc, par y croire: il est alors perdu. Il devient ce valet stupide, ce cireur amusant; un animal domestique [...] il devient en somme le complice de sa propre oppression. 
En effet Monsieur Thôgô-gnini est le complice non seulement de son propre avilissement mais aussi de l'oppression de ses compatriotes par les Blancs, à laquelle il participe avec ardeur. Et il s'agit, en effet, d'un "avilissement consentant," c'est-à-dire d'une aliénation consciente.

Mais cette aliénation consciente et flagrante qui commence à agacer les compatriotes ne saura durer indéfiniment. Et le peuple qui en a assez du comportement autophage et arrogant de Monsieur Thôgô-gnini se saisit de lui, lui prend son argent, le transforme en un objet d'une farce grossière, un véritable symbole de l'aliénation culturelle. C'est ainsi que dans sa tenue de jute on "lui blanchit le visage, les mains, lui rougit les lèvres [...]" $(\mathrm{V}, \mathrm{p} .81)$, et lui colle sur la poitrine une pancarte portant "CHACUN POUR SOI." On l'entraîne dans cette parure devant le tribunal qu'il aurait organisé dans le but de punir N'Zekou pour avoir osé lui demander de payer sa dette. Et les chaînes de N'Zekou, c'est à lui maintenant que la foule les passe. La pièce se termine ainsi sur cette mise à la chaîne de Monsieur Thôgô-gnini.

La fin de la pièce ne nous paraît pas bien menée. L'aliénation culturelle telle qu'elle se présente chez Monsieur Thôgô-gnini est un délit très grave d'autant plus que le personnage est pleinement conscient de son aliénation et s'en enorgueillit avec arrogance car cette aliénation représente à ses yeux l'indice de sa supériorité face à ses compatriotes qui n'ont pas la capacité de se blanchir. L'aliénation de Monsieur Thôgô-gnini est un délit qui mérite un projet correctionnel beaucoup plus sévère qu'une mise à la chaîne. C'est que même enchaîné, le personnage ne semble pas se rendre compte de la nature de ses forfaits. Loin d'un repentir quelconque, il s'étonne qu'on ose le blâmer ou l'accuser de quoi que ce soit. L' "arrestation" de Monsieur Thôgô-gnini nous paraît donc comme constituant essentiellement un sursis aux activités du personnage, activités qui reprendront leur cours dès que les chaînes seront enlevées. C'est pour cela qu'il aurait fallu une fin beaucoup plus susceptible de faire ouvrir les yeux au personnage, une fin où l'on assistera, par exemple, non seulement à la saisie de tous les biens du personnage, mais aussi à sa condamnation à l'exil.

La deuxième pièce que nous étudions sous l'aliénation consciente - La Secrétaire particulière - reprend, en le dépeignant avec vigueur, un certain aspect de l'aliénation culturelle que Bernard Dadié ne fait qu'évoquer dans Monsieur Thôgô-gnini: 1'aliénation vestimentaire. La Secrétaire particulière se distingue aussi de Monsieur Thôgô-gnini du fait qu'alors que celle-ci présente l'aliénation culturelle chez les Africains comme un phénomène qui se produit au fur et à mesure que le contact entre l'Europe et l'Afrique s'approfondit, celle-là présente l'aliénation culturelle telle 
qu'elle se manifeste en Afrique indépendante. Mais dans la pièce aussi l'aliénation culturelle apparaît surtout comme étant le résultat de la colonisation de l'Afrique par l'Europe.

Cette aliénation, un peu comme dans Monsieur Thôgô-gnini, est surtout vestimentaire. Mais si l'aliénation est vestimentaire dans Monsieur Thôgô-gnini, elle est autre chose aussi: elle traduit l'oppression criminelle du peuple par Monsieur Thôgô-gnini au nom de l'argent, en faisant fi de tout ce qui constitue la philosophie de vie africaine. Elle reste par contre largement vestimentaire dans La Secrétaire particulière. Néanmoins, tout comme Monsieur Thôgô-gnini s'habille en occidental pour mieux souligner son importance et s'imposer à ses compatriotes, Monsieur Chadas, le personnage principal, et le Chef de service dans La Secrétaire particulière, s'habille toujours en tenue européenne, et interdit à ses employés de se présenter en tenue africaine. Son raisonnement peu logique fait remarquer jusqu'à quel point Chadas admire la culture européenne et méprise la sienne. Son aliénation est consciente. Ainsi déclare-t-il à son employé, Jacques, coupable de venir au bureau en costume traditionnel:

[...]Ne savez-vous pas que le Français est notre langue officielle? Comment voulez-vous parler la langue française sans porter une cravate? Je vous le répète. Et à vous aussi mesdemoiselles. Pour les hommes, pas de tenue correcte sans le pantalon, la veste, la cravate ou le noeud papillon (il touche le sien). Pour les femmes, toujours une robe et une robe à la mode autant que possible (I, 2, pp. 16-17).

Bien que Chadas sache que le costume européen ne convient pas en Afrique à cause du climat du continent, et bien que lui-même étouffe de chaleur dans sa veste et sa cravate, il refuse d'enlever sa veste car "ce serait incorrect" dit-il (II, 3, p. 35). Il reconnaît d'ailleurs, bien qu'indirectement, qu'il est "esclave des manières des Blancs" (Ibid.). Mais cet état d'esclave lui paraît beaucoup plus important et beaucoup plus acceptable qu'une situation où il soulignera sa liberté et fera valoir sa propre culture à travers une tenue africaine qui est précisément commode au climat du continent.

C'est que Monsieur Chadas ne veut pas déchoir à ses propres yeux. Le costume européen est pour lui une manière de se montrer bien "civilisé," et partant très important comme homme. Son titre de chef de service, c'est-à-dire de chef de bureau paraît lui imposer son comportement. Le bureau, à proprement parler, a été une création du 
colonialisme. Avant la colonisation, les affaires publiques en Afrique se réglaient souvent en plein air dans le centre du village ou dans les cours des chefs qui faisaient ainsi office de "salles" à palabres. Les affaires étaient débattues au vu et au su de tous et tout le monde pouvait y participer. Ce n'était plus le cas en Afrique coloniale où les affaires publiques étaient particulièrement dirigées par les colonisateurs dans des bureaux. Ces chefs de bureau occidentaux portaient souvent des costumes européens. Or lorsque certains Africains comme Chadas sont devenus chefs de service à la fin de la colonisation, ils ont cru, naïvement, que le travail de bureau ne saurait se faire sans costume européen. Autrement dit, ils ont cru que sans ce costume ils ne pourraient pas avoir la même importance et le même respect qu'avaient les chefs de service européens.

D'autre part, puisqu'en Afrique coloniale le costume européen était principalement porté par les colonisateurs, ce costume lui-même était aux yeux de la plupart des Africains le symbole de la colonisation, c'est-à-dire de la domination des Noirs. Etant donné aussi que les colonisateurs détenaient l'autorité sur les Noirs, le costume qui les désignait en particulier devenait par extension le symbole de leur "supériorité" à l'égard des Noirs. C'est précisément cette supériorité conférée surtout par le vêtement que les Chadas veulent exercer à l'égard de leurs compatriotes. Mais en le faisant, ils rejettent leur culture et se rejettent en même temps. Un Chadas qui s'habille en occidental et qui rejette le costume africain est un Chadas sans une véritable identité, un Chadas suspendu entre deux cultures: la culture européenne à laquelle il aspire et la culture africaine à laquelle il renonce. Il n'appartient pas à l'une; il n'appartient plus à l'autre. C'est ce procédé d'auto-déchirement que Frantz Fanon évoque lorsqu'il parle de "la tentative de l'homme de couleur de fuir son individualité, de néantiser son être-là." En fait, bien qu'il aspire à la culture occidentale, bien qu'il «tente de fuir son individualité et de néantiser son être-là,» Chadas ne réussira jamais à faire sienne la culture européenne car, comme le fait remarquer Albert Memmi:

[...] On ne s'arrache pas ainsi de soi-même, on ne peut pas vivre impunément en se haïssant [...] Et surtout, le Blanc n'a pas voulu se laisser imiter. Ne 1'oublions jamais: 1'assimilation est [...] refusée par l'oppresseur $[\ldots]$

Or puisque l'aliénation culturelle en Afrique est un procédé par lequel certains Africains rejettent leur culture et s'efforcent d'assimiler la culture européenne, et puisque le Blanc ne veut surtout pas se laisser imiter car, accepter l'imitation par l'homme noir équivaudra à conférer à l'imitateur un certain statut d'égalité, ce qui 
compromettra la conscience de supériorité que le Blanc a souvent face au Noir, il s'ensuit que l'aliénation est un exercice ambigu, presque inutile. C'est un exercice où le Noir se détruit en même temps qu'il cherche à se faire reconnaître. C'est un exercice enfin qui assure la disparition du Noir qui veut "paraître."

C'est finalement ce qui arrive à Monsieur Chadas. On l'expulse du bureau et de la société où il veut imposer son importance. Mais cette expulsion n'est pas le résultat direct de 1'aliénation culturelle du personnage qui se manifeste par le préjugé vestimentaire. Cependant, il est vrai que la position de chef de service qu'occupe Chadas est une position d'autorité. Cette autorité s'exprime à travers le costume européen et elle favorise la corruption sociale dans la mesure où elle permet au personnage de se procurer tout ce qu'il veut par des moyens souvent injustes ou malhonnêtes. Chadas profite pleinement de son autorité. Il intimide Avocè, un chômeur que sa voiture renverse dans la rue, et bafoue Denise, l'avocate de la victime. Il réduit Nathalie, sa secrétaire particulière, en objet du plaisir sexuel jusqu'au moment où la grossesse de Nathalie sonne le scandale qui met fin à l'autorité de Chadas.

Comme on le voit donc, l'aliénation consciente est un délit grave qui menace l'existence même de l'Afrique. C'est un délit d'autant plus sérieux qu'il est commis par les personnages qui sont haut placés dans la société. Vu leur rang social, la préoccupation principale de ces personnages aurait dû être de sauvegarder et de perpétuer la culture africaine face à la culture européenne mise en avant comme la nouvelle valeur de référence par le fait colonial. Mais loin de tenter de faire valoir la culture africaine, les Thôgô-gnini et les Chadas sont comme emballés et emportés par cet ouragon européen qu'est le fait colonial. Ils ne pensent alors qu'à fuir leur individualité africaine, à s'arracher d'eux-mêmes suivant cette tentative lucide mais toujours manquée de suicide du moi.

\section{Aliénation inconsciente}

Dans l'aliénation inconsciente, l'aliéné social est sensibilisé aux avantages que favorise la culture européenne. Il veut profiter de ces avantages, et en le faisant, il ne pense pas au mauvais effet que son comportement pourrait avoir sur sa propre culture: l'hémorragie inévitable de cette culture. L'aliéné inconscient est séduit par les apparents avantages que lui présente la culture occidentale, mais il ne prend pas une décision lucide et clairement consciente de renoncer à sa culture. Il tend soit à oublier momentanément sa culture au profit du plaisir de l'instant, comme c'est la cas dans Béatrice du Congo de Bernard Dadié, soit à la conjuguer avec la culture étrangère, 
comme c'est le cas dans Trois prétendants...un mari de Guillaume Oyono-Mbia. Nous tâcherons donc, au cours de l'étude de ces deux pièces, de faire bien saisir le mécanisme de l'aliénation inconsciente.

Tout comme dans Monsieur Thôgô-gnini, Bernard Dadié met l'accent, dans Béatrice du Congo, sur le résultat de la rencontre entre l'Europe et l'Afrique: la désintégration de la culture africaine.

Lorsque les Européens (les Portugais nommés les Bitandais dans la pièce) arrivent au Zaïre, ils laissent entendre qu'ils sont venus rechercher et établir des rapports amicaux entre le Bitanda et le Zaïre. Pour leur part, les Zaïrois recourant à la philosophe africaine d'une fraternité universelle, accueillent les Bitandais à bras ouverts car "Tout étranger est un envoyé des dieux" (I, 2, p. 32), comme le dit le roi du Zaïre. Mais à peine arrivent-ils au pays que les Bitandais dévoilent, presque avec arrogance, le véritable objet de leur présence: il s'agit de transformer le Zaïre en satellite du Bitanda, voire de faire du Zaïre une propriété privée du Bitanda. Jugeant le Zaïre primitif, barbare et sans civilisation, les Bitandais surnomment leur projet d'appropriation une mission civilisatrice.

Cette mission civilisatrice est présentée par les Bitandais comme étant dictée par l'amitié qu'ils éprouvent pour les Zairrois. Mais comme on le verra tout à l'heure, il s'agit d'une amitié spécieuse et coûteuse qui ne saura s'établir qu'au prix de la perte de tout ce qui constitue la spécificité culturelle du Zaïre, une amitié garantie presque exclusivement par l'aliénation culturelle chez les Zaïrois. C'est ainsi qu'au nom de l'amitié, les Bitandais obligent les Zaïrois à transformer le nom de Mbanza Congo, capitale du Zaïre, en San Salvador qui est "plus facile à prononcer" (II, 1, p. 71). Alors que Mbanza Congo signifie quelque chose dans le contexte zaïrois, San Salvador est tout à fait déplacé et peu signifiant dans le même contexte. Le même coup qui oblitère Mbanza Congo transforme les noms des notables en Duc, Baron, Marquis, Comte, Vicomte. Le roi du Zaïre devient Dom Carlos 1er, un nom qui n'a de sens ni pour lui ni pour son peuple. Ce que tout cela signifie, c'est une perte d'identité grave, la «mort» même des personnages car en Afrique, nommer ne veut pas seulement dire désigner quelqu'un par un tel ou tel nom. Nommer veut dire aussi saisir tout l'être, atteindre l'essence même de l'être. C'est presque créer, saisir au vif la spécificité de l'être. On comprend donc qu'en Afrique les noms reflètent ou renvoient souvent aux circonstances de naissance. On comprend aussi l'amertume avec laquelle Aimé Césaire décrie la même situation historique où les colonisateurs obligent les Africains 
à renoncer à leurs noms africains au profit des noms européens. Dans une de ses pièces, un personnage nommé Rebelle s'écrie, angoissé:

"Mon nom: offensé; mon prénom: humilié; mon état: révolté; mon âge: l'âge de la pierre."

Le coup qui renverse les noms africains en mettant les noms étrangers à leaur place terrasse aussi un certain aspect culturel important de l'Afrique: le système de nomination. Les personnages africains à qui on donne des noms étrangers paraissent enfin comme étant étrangers à eux-mêmes. En fait ils paraissent comme étant déracinés, voire coupés de leur propre essence, leur propre souche. Ils flottent ainsi dans l'air, entre deux mondes distincts: le monde africain d'où ils sont arrachés par le fait colonial, et le monde européen qui leur est interdit en raison de leur soi-disant primitivité et leur manque de civilisation. C'est pourquoi les Bitandais se rient du roi du Zaïre et se moquent du projet de son voyage au Bitanda.

Mais la perte d'identité ne se manifeste pas seulement dans le rejet des noms africains. Elle apparaît aussi dans l'abandon des traditions africaines. Pour pouvoir garder l'amitié du Bitanda, le roi du Zaïre est obligé de rompre avec le passé, de détruire les fétiches. Il doit aussi renoncer à la polygamie malgré le fait qu'il est bien convaincu de la nécessité socio-politique de cette coutume. Il doit également abandonner la religion traditionnelle pour le christianisme européen, et finalement il ordonne aux autres Zaïrois de l'imiter en tout:

En tant que père de la Nation, j'intime l'ordre à tous de me suivre aveuglément (II, i, p. 78).

En effet, à l'exception de l'héroïne, Dona Béatrice, ils le suivent aveuglément. C'est que Dona Béatrice constate l'état de désagrégation sociale où sombre le Zaïre depuis la présence des Bitandais, et décide de prévenir le roi de sa méprise en faisant aux Bitandais "une confiance totale...absolue, chrétienne"(Ibid., p. 87).

Mais l'entretien entre Dona Béatrice et le roi ne fait que révéler la nature profonde de l'aliénation du roi. On apprend que le roi est dorénavant sensibilisé au culte de l'argent et ne pense plus qu' à devenir aussi riche que le roi du Bitanda, au détriment de son peuple: "Je vais m'édifier la plus colossale des fortunes" (II, i, p. 91), dit-il en comptant et recomptant son argent. N'ayant plus de confiance en son propre pays, il doit garder sa fortune au Bitanda. Il vante sa garde blanche et se montre fier de ce que 
l'armée bitandaise veille sur le pays pour le protéger contre son peuple. Il met une distance grandissante entre lui-même et son peuple. Il décrit celui-ci comme "des envieux" et comme "le flot des gueux" (Ibid., p. 85), et veut "faire dresser deux, trois, quatre enceintes autour de [ses] palais" (Ibid., p. 85). A Dona Béatrice qui insiste pour lui parler il déclare:

Non! Je ne veux plus rien entendre. Ce n'est plus à moi de vous écouter, mais à vous de m'écouter (II, 1, p. 86).

Autrement dit, le roi supprime la situation où le dialogue existait entre lui et le peuple, et la remplace par une nouvelle situation, celle qui existe entre le maître et l'esclave et qui ne permet presque pas de véritable dialogue. On ne s'étonne donc pas que le roi devienne esclavagiste, vendant le même peuple qu'il devrait protéger. Et comme le dit Dona Béatrice, le roi n'est plus véritablement un Zaïrois mais “Un Bitandais de couleur" (Ibid., p. 91).

Il est vrai que le roi du Zaïre est devenu "un Bitandais de couleur," mais il convient de souligner que le roi n'est pas du tout conscient de son aliénation. Il est complètement envoûté par les paroles doucereuses d'amitié que lui lancent sans cesse les Blancs, et il n'est pas en mesure de saisir sa véritable situation. Il s'agit donc d'un cas d'aliénation inconsciente.

Cependant, le roi ne demeure pas jusqu'au bout aliéné de sa culture. En fait, à la longue période d'aliénation inconsciente se succède une phase de désaliénation lorsque le roi prend conscience de la véritable nature de l' "amitié" des Bitandais. Il comprend que cette "amitié" n'est pas différente d'une hostilité déclarée de la part des Bitandais. C'est d'abord que non seulement les Bitandais entretiennent des guerres civiles dans le pays et vendent des armes à toutes les régions engagées dans le conflit, mais aussi ils enlèvent deux membres de la famille royale pour les vendre en esclavage. Le roi comprend aussi que le contrat d'amitié qu'on lui avait fait signer voulait dire le renoncement au Zaire au profit du Bitanda. Du coup le roi se rend compte qu'il n'a plus de pays, et qu'il est maintenant "étranger sur [son] propre sol devenu sol étranger" (III, 3, p. 130). Le roi comprend aussi qu'il n'a plus d'autre choix qu' à retourner à ses anciennes traditions et aux dieux des ancêtres, et tel un fils prodigue, il demande aux ancêtres de lui pardonner. Son repentir est sincère, et sa douleur amère naît précisément de sa déception profonde à l'égard des Bitandais: 
[...]J'entends me réconcilier avec les miens, avec mon peuple, rétablir l'unité du pays mis au pillage par les traitants, ruiné par les guerres [...] Pauvre Zaïre, tout remettre debout, sur pied [...] Ramenez-moi mes dieux, les dieux de mes ancêtres, ceux qui ne me sont pas prêtés et qui me comprennent (III, 3, p. 127).

Un peu plus loin, la mort dans l'âme, il s'accuse de ses crimes:

Branche séchée dans la forêt vivante, la touffe d'herbe en train de pourrir l'eau, de tuer les poissons; vieux sorcier qui se nourrit de ses propres enfants, des années durant j'ai régné sur des cadavres, des enfants condamnés avant même d'avoir été conçus, condamnés pour avoir vu le jour sur les bords du Zaïre, dans le royaume du Zaïre. J'ai été le souverain des morts, et c'était pour ça... (III, 3, pp. 132-133).

L'indication de scène précise que le roi, en disant ces derniers mots, "tâte une bourse" c'est-à-dire l'argent qu'il a reçu des Bitandais. L'argent, la croix et le grand cordon qu'il porte au cou deviennent tous pour lui des signes accusateurs de ses crimes, de son aliénation. Il enlève donc ce qu'il porte au cou, se défait de ses habits d'emprunt et affirme son retour "à l'Afrique traditionnelle qui ne portait aucune corde au cou" (Ibid., p. 133). Il enlève les drapeaux bitandais et $\mathrm{y}$ met le feu. Un conseiller bitandais tire sur lui et la désaliénation du roi se solde ainsi par la mort du personnage.

La mort du roi, tout comme celle de Dona Béatrice qui suit peu après, pourrait, à première vue, sonner le triomphe du colonialisme et de l'aliénation culturelle à laquelle le colonialisme a donné naissance, mais ce n'est qu'en apparence, et de toute façon, un triomphe éphémère. En vérité la mort du roi semble ouvrir les yeux aux autres Zaïrois sur la vraie nature des rapports qui existent entre le Zaïre et le Bitanda. Elle paraît convertir le doute que les Zaïrois ont sur la bonne foi des Bitandais en évidence concluante et décisive de la mauvaise foi des Bitandais.

Cette prise de conscience par le peuple contribue à unifier le pays en mettant ainsi fin aux guerres civiles qui ont été provoquées et entretenues par les Bitandais. Dorénavant le peuple est comme poussé par un seul désir: l'expulsion des Bitandais hors du Zaïre. Lorsque la mort de Dona Béatrice se produit peu après celle du roi, le désir du peuple se traduit en action militaire violemment annoncée par les crépitements de tam-tams et par le chant martial. Ainsi ces deux morts - celle du roi et celle 
de Dona Béatrice - se conjuguent-elles pour exprimer la désaliénation culturelle du Zaïre.

La deuxième pièce que nous étudions sous l'aliénation inconsciente - Trois prétendants...un mari - se distingue bien de trois autres pièces dont nous avons parlé, du fait que l'aliénation n'est pas présentée dans Trois présendants...un mari comme étant l'affaire surtout d'un seul personnage principal. L'aliénation culturelle n'est pas ici surtout l'affaire d'une classe dirigeante et "privilégiée" qui aurait été influencée par le contact direct avec la culture européenne. L'aliénation concerne plutôt toute une classe de villageois, particulièrement les vieillards qui sont censés être gardiens de la tradition, c'est-à-dire de la culture africaine. L'aliénation apparaît chez eux car ils se mettent dans une situation où, loin de s'efforcer de protéger la culture africaine, ils tendent à la supprimer pour leurs propres profits personnels.

Ce qui a produit ce changement chez les villageois, c'est, comme chez les autres Africains, le contact avec l'Europe qui a bouleversé les rapports sociaux et a installé un nouveau mode de vie exprimé surtout à travers des considérations monétaires. Il est vrai que les villageois africains ne connaissaient pas les Blancs de première main. Ils les voyaient de loin et de manière peu régulière puisque les Européens s'installaient souvent en ville par opposition au village. Mais les villageois savaient aussi que dans leurs costumes européens, les colonisateurs représentaient en Afrique l'autorité et la réussite sociale. Les Blancs étaient tous aux yeux des villageois des hommes riches, de grands hommes, et des hommes de bureau.

Or en Afrique post-coloniale où certains Africains deviennent fonctionnaires et travaillent dans des bureaux, les villageois reportent sur ces Africains l'image qu'ils se faisaient des Blancs. Ces fonctionnaires africains deviennent à leurs yeux des hommes riches, de grands hommes, bref "de vrais blancs." Ils représentent ainsi la réussite sociale mesurée surtout au compas de l'argent. Mais puisque les villageois ne sont pas en mesure de prétendre au poste de fonctionnaire et se faire "riches" pour mieux vivre la vérité de l'Afrique indépendante, il ne leur reste qu' une seule issue: vivre cette vérité par une sorte d'osmose. C'est-à-dire se lier en parenté à un employé de bureau. Celui-ci est invité à verser une somme énorme, comme dot, à s'occuper de tous les besoins des parents de la jeune fille. C'est précisément ce qui se passe dans Trois prétendants... un mari où les villageois voient dans le mariage de Juliette un moyen de s'enrichir, de devenir de grands hommes grâce à la dot extravagante que le mari éventuel doit verser. 
La dot a toujours existé en Afrique. En Afrique traditionnelle la dot avait surtout une valeur symbolique et elle consistait en bien donné comme cadeau par un mari éventuel à la famille de la jeune fille pour exprimer sa gratitude à cette famille en lui donnant la jeune fille en mariage, et pour remercier les parents de la jeune fille du soin qu'ils ont pris à élever leur enfant. La valeur du bien qui constituait la dot n'était pas très importante. Ce qui comptait, c'était surtout son aspect symbolique. La dot légalisait le mariage.

Or en Afrique indépendante où l'argent détermine désormais les rapports sociaux, la dot, elle, prend des valeurs monétaires très importantes. C'est que les villageois qui protègent l'institution de la dot voient dans cette institution le moyen de mener une vie honorable dans cette Afrique où l'argent fait la loi et l'honneur des gens. Mais en attribuant à la dot des valeurs monétaires extravagantes, ils contribuent ainsi à dénaturer cette institution de la dot dont ils sont les gardiens. C'est ainsi que les villageois se trouvent dans une situation où ils sont coupables d'aliénation culturelle car leur conduite équivaut en quelque sorte au renoncement à leur identité culturelle. En voulant donner Juliette au plus offrant, c'est-à-dire au prétendant qu'ils jugent le plus capable de les enrichir eux-mêmes, ils convertissent Juliette en une espèce de marchandise. Les villageois paraissent ainsi comme des pères dénaturés qui transforment le rapport filial qui devrait exister entre père et enfant en celui qui existe entre producteur et son produit, et nous présentent du coup une forme classique de l'aliénation marxiste

En fait les villageois ne voient Juliette qu'en fonction des profits ou des biens qu'ils recevront grâce à son mariage. La jeune fille a surtout pour eux une sorte de valeur d'échange, un objet qui permet d'acquérir quelque chose d'autre. C'est ainsi que le père de Juliette, Atangana, s'enorgueillit en voyant que les prétendants se multiplient à cause de l'éducation de Juliette:

(Se frappant fièrement la poitrine) Juliette est, en effet, une fille digne d'un père comme moi, et je disais bien, en l'envoyant au collège, que cela me rapporterait $(I, 1$, p. 26$)$.

Abessolo, grand-père de Juliette, qui préfère un prétendant fonctionnaire, explique à son fils l'importance d'avoir un fonctionnaire pour gendre:

Rappelle-toi les longues attentes qu'on te fait subir devant les bureaux administratifs, parce que personne ne te connaît! Or, maintenant que tu 
auras ce grand homme pour gendre, on s'empressera de te servir. (Ibid., p. 27).

Ondua, l'oncle ivrogne de Juliette, qui est toujours arrêté pour ivresse publique, voit déjà, dans le fonctionnaire son protecteur personnel contre les agents de police. Et lorsque Atangana déclare à Juliette qu'il y a déjà deux prétendants à sa main à cause de son instruction et de sa valeur et lui signifie en même temps que "les deux dots décideront" (2, p. 29), la jeune fille s'écrie, humiliée et désemparée:

Mais comment? Suis-je donc à vendre pour que vous vous croyiez obligés de me donner au plus offrant? Ne puis-je donc pas être consultée pour un mariage qui me concerne? (I, 2, p. 29).

Un "producteur" ne consulte pas son «produit» avant de le vendre. On comprend donc la consternation générale des villageois devant cette indignation de Juliette qui veut qu'on la consulte au sujet de son mariage. En effet le désir de Juliette en tant qu'individu ne les intéresse pas. Ce qui les intéresse, c'est ce qu'ils recevront, la richesse qui leur reviendra en cédant Juliette en échange contre la dot.

Et puisque Juliette est instruite, la dot que les villageois exigent des prétendants prend une valeur astronomique. Non seulement le fonctionnaire, Mbia, le deuxième prétendant, doit verser deux cent mille francs, mais il doit également procurer aux villageois tout ce qu'ils désirent: des bicyclettes, de grands pagnes, des lits en fer, des fusils, des machines à coudre, des sacs de riz... Et lorsque la sainte loi de l'exogamie, soulevée par Abessolo, menace de compromettre le mariage entre Juliette et le fonctionnaire qui ont un certain lien de parenté, les villageois décident d'abolir cette parenté, c'est-à-dire de détruire la tradition qu'ils devraient protéger. C'est qu'ils sont déjà en train de boire la bière apportée par le fonctionnaire, et comme le souligne Ondua, "Toute la parenté du monde vaut-elle la bière?" (II, 1, p. 38). Le chef du village, Mbarga, ne dit pas autre chose, malgré sa tournure hypothétique:

Ecoutez-moi tous! Je suis le chef? Mbia, le fonctionnaire que voici, veut épouser notre fille Juliette. (Négligemment) Quelques liens de parenté pourraient empêcher ce mariage, je l'admets. (Fort) Mais quoi? Evincerions-nous un fonctionnaire pour de pareilles raisons? $\mathrm{Ne}$ mérite-t-il pas des égards? (II, 1, p. 39). 
Les villageois admettent avec chaleur que le fonctionnaire mérite des égards, et dès que Mbarga énumère les bénéfices qui leur reviendront du mariage, la cause de la parenté est définitivement perdue.

Un de ces bénéfices, ce qui souligne aussi l'aliénation chez les villageois, est leur espoir que grâce au mariage, le fonctionnaire les "fera manger et boire comme des blancs au 'Relais' de Sangmélina" (II, 1, p. 39), ce restaurant que fréquentent les Blancs au Cameroun. Il s'agit là d'un désir détourné chez les villageois d'être "assimilés" aux blancs, enfin de devenir "blancs," car leur vrai état de villageois ne leur permet pas de se considérer comme de grands hommes. En s'assimilant ainsi aux blancs, ils pourraient finalement devenir importants à leurs propres yeux dans leurs nouvelles personnalités aliénées.

C'est aussi par le même désir de ne reconnaître leur propre valeur qu'en se voyant à travers autrui, qu'en se voyant en blanc, qu'ils méprisent Ndi, le premier prétendant, un "simple" cultivateur comme eux, et tremblent devant les menaces de Mbia, un fonctionnaire qui, pour les villageois mérite le respect car c'est "un vrai blanc." Le dédain qu'ils ont donc pour Ndi à qui ils décident de tenir tête en le bravant malgré le fait qu'ils se trouvent momentanément dans l'incapacité de lui rendre sa dot, ne s'explique que par le fait que Ndi leur ressemble. Ce n'est qu'un villageois comme eux. Il s'agit donc d'un mépris de soi, d'une tentative désespérée de s'arracher de soimême, ce qui traduit finalement un cas éloquent d'aliénation. Mais le dramaturge ne permet pas aux villageois de réaliser leur rêve de "se blanchir," c'est-à-dire de devenir de grands hommes en cédant Juliette au plus offrant. En fait à la fin de la pièce, Juliette qui réussit à déjouer les manoeuvres des villageois épouse son fiancé "sans dot."

Cependant, le fait même que l'aliénation culturelle se manifeste aussi chez les villageois, les gardiens principaux de la culture africaine, montre jusqu' à quel point le contact entre l'Afrique et l'Europe a produit des effets troublants sur l'Afrique. C'est comme s'il s'agissait de montrer que l'aliénation culturelle est une maladie générale qui ronge toutes les classes sociales du continent.

Mais il est vrai que les villageois ne se rendent pas compte de leur aliénation, et qu'il s'agit chez eux d'une aliénation inconsciente. Ils ne se rejettent pas consciemment. Ils aspirent seulement à participer au "progrès" social qu'ils constatent autour d'eux et qui se détermine par l'acquisition de l'argent. Pour ce faire, les villageois tentent de renforcer la valeur de la dot, c'est-à-dire de transformer la valeur symbolique 
et culturelle de la dot en une nouvelle valeur "capitaliste" qui devrait leur apporter de la richesse. Il s'agit de la part des villageois d'une tentative de conjuguer la valeur de la dot en Afrique traditionnelle avec sa nouvelle valeur en Afrique post-coloniale. Autrement dit, il s'agit de se servir d'une institution traditionnelle comme un moyen d'atteindre la vérité de l'Afrique indépendante. Mais tentative vaine car on ne réalise pas son propre "progrés" en s'arrachant de soi-même, en se néantisant. C'est ce fait que Guillaume Oyono-Mbia souligne bien par le mariage de Juliette "sans dot."

Bien qu'il y ait dans toute aliénation, un certain élément du rejet de soi, ce rejet de soi apparaît clairement dans l'aliénation inconsciente comme étant le résultat de l'envoûtement que la culture européenne opère chez les Africains. Dans Béatrice $d u$ Congo, l'envoûtement est activement entrepris par les Européens qui réussissent à obliger les Zaïrois et surtout le roi du Zaïre à renoncer à la culture africaine, au profit de la culture européenne. Dans Trois Prétendants...un mari, au contraire, l'envoûtement est passif, et les villageois qui pensent à "se blanchir" veulent simplement profiter de la nouvelle situation du progrès économique qui a été mise en relief à la suite de l'épreuve coloniale. Mais dans la première pièce comme dans la deuxième, les personnages qui sont atteints d'une aliénation inconsciente finissent par se rendre compte de leur situation, et par rectifier la situation en quelque sorte. Ainsi à l'aliénation qui a été activement entreprise au Zaïre se succède la désaliénation active, voire agressive des Zaïrois. Et à l'envoûtement passif et au désir vague des villageois de devenir "blancs" grâce à la dot que le mariage de Juliette doit leur apporter se succède leur prise de conscience sobre du mariage de Juliette "sans dot."

\section{Conclusion}

Qu'il s'agisse donc d'une aliénation consciente ou d'une aliénation inconsciente, l'aliénation culturelle en Afrique traduit toujours le rejet de la culture africaine au profit de la culture européenne. L'aliéné africain se sépare de sa propre culture, la seule culture qu'il connaissait avant la colonisation, et remplace cette culture avec la culture occidentale à laquelle le colonialisme l'expose.

Mais si dans l'aliénation consciente, la séparation est volontairement et activement entreprise par le personnage comme un moyen d'affirmer sa supériorité à ses compatriotes, dans l'aliénation inconsciente le rejet du moi est chez le personnage une opération passive. Loin de vouloir activement rejeter sa culture au profit de la culture européenne pour bien souligner son importance en tant qu' être humain, comme le fait l'aliéné conscient, l'aliéné inconscient subit son aliénation presque comme une 
épreuve imposée par l'évolution historique de son milieu. L'aliéné inconscient ne cherche pas à arrêter cette évolution historique, et peut-être parce qu'il n'est pas en mesure de l'arrêter, vu le bouleversement total des valeurs de référence dans lequel il est engouffré à la suite du fait colonial. Alors que les Thôgô-gnini et les Chadas vivent activement, et avec passion, leur aliénation car cette aliénation met clairement en relief, du moins à leurs yeux, leur nouvelle valeur humaine très importante, le roi du Zaïre et les villageois subissent leur aliénation comme une espèce de sort qui leur a été jeté. On comprend donc que le roi du Zaïre demande à ses compatriotes de le suivre "aveuglément" dans son aliénation, tout comme il suit aveuglément les Bitandais. On comprend également que les villageois voient dans leur situation de pères dénaturés, dont ils n'ont nullement conscience, le moyen de devenir "de vrais blancs," c'est-àdire d'atteindre le progrès socio-économique, ce qui leur permettra finalement de vivre la vérité de l'Afrique post-coloniale.

Le roi du Zaïre et les villageois demeurent, tout au cours des pièces, largement inconscients de la véritable situation dans laquelle ils se trouvent. Quand, enfin, le roi du Zaïre prend conscience de sa situation, il se rend compte que l'aliénation dans laquelle il s'est fourré a été le résultat d'un malentendu entre les Bitandais et lui:

[...]Nous avons dialogué sans nous comprendre, nous avons parlé sans tenir le même langage, vécu dans la même maison sans nous connaître [...] (Béatrice du Congo, III, 3, p. 127).

Cette prise de conscience par le roi du Zaïre est vite suivie des actes entrepris pour détruire l'aliénation. De tels actes ne se manifestent pas, cependant, chez les villageois dont l'aliénation est demeurée inconsciente, passive, voire presque discrète jusqu'à la fin de la pièce. Ils ne se rendent pas bien compte de ce qui se passe autour d'eux en ce qui concerne les péripéties qui entourent la dot pour la main de Juliette. Et la remarque hypothétique faite par Atangana à sa fille Juliette, résume précisément la situation dans laquelle se trouvent les villageois:

[...] J'aurais peut-être mieux fait de te donner pour rien...à ton écolier, par exemple! (Trois prétendants... IV, 4, p. 95).

Ce qu'Atangana conçoit comme une possibilité abstraite, c'est précisément une réalité qu'il vient de vivre sans s'en rendre compte. 
On pourrait finalement dire qu'en ce qui concerne l'aliénation inconsciente, les dramaturges laissent entendre la possibilité du rachat des personnages aliénés. Les personnages finissent par saisir leur véritable situation et par comprendre le mauvais rôle qu'ils jouent face à leur propre culture. Quant aux aliénés conscients aucun rachat n'est plus possible. Leur aliénation est volontairement choisie. Leur perte définitive est certaine. Et il s'agit d'une perte dans le sens le plus profond du terme. Il s'agit d'une perte totale à laquelle tout abri est interdit. Il est vrai que les personnages rejettent leur propre culture, mais la culture européenne à laquelle ils aspirent leur est refusée. Ils sont ainsi suspendus dans l'air, sans "patrie" aucune, et tel est en définitive le drame de l'aliénation consciente.

\section{Notes}

1 Thesaurus linguae latinae, editus auctoritate et consilio Academiarum quinque Germanicarum (Leipzig: Teubner, 1900), Vol. I, cols. 1558-1560.

${ }^{2}$ Nous n'ignorons pas que l'aliénation peut être volontairement choisie par un individu pour des raisons personnelles. Mais cette aliénation reste aux yeux des autres une situation peu désirable.

${ }^{3}$ Richard Schacht, Alienation (New York: Doubleday \& Company, Inc., 1970), p. 183. Voir aussi:-Melvin Seeman, "On the meaning of alienation," American Sociological Review Vol. 24, No. 6 (December 1959), p. 788; Gwynn Nettler, "A measure of alienation," American Sociological Review Vol. 22, No. 6 (December 1957), pp. 672-674. 65.

${ }^{4}$ Bernard Murchland, The New Iconoclasm (New York: Doubleday \& Co., Inc., 1973), p.

${ }^{5}$ Aimé Césaire, Cahier d'un retour au pays natal (Paris: Présence Africaine, 1983), p. 56. Voir aussi : Frantz Fanon, Peau noire masques blancs (Paris: Seuil, 1952), p. 38; Albert Memmi, L'homme dominé (Paris: Gallimard, 1968), pp. 64-65.

${ }^{6}$ Un examen soutenu de la théorie d'aliénation chez Karl Marx dépasse le propos de notre étude. Mais on pourrait consulter à profit: K. Marx, F. Engels, Selected works, 2 vols. 
(Moscow: Foreign Language Publishing House, 1949); Bertelle Ollman, Alienation: Marx's conception of man in capitalist society (Cambridge: Cambridge University Press, 1973), p. 132; Joachim Israel, Alienation from Marx to modern sociology (Boston: Allyn \& Bacon, Inc., 1971), pp. 81-84; Svetozar Stojanovic, Between Ideals and Reality: A critique of socialism and its Future, traduit par Gerson Sher, (London: Oxford University Press, 1973), pp. 19-32.

${ }^{7}$ André Lalande, Vocabulaire technique et critique de la philosophie (Paris: P.U.F., 1988).

8 Paul Robert, Le Grand Robert de la langue française: Dictionnaire alphabétique et analogique de la langue française, 9 tomes, tome I, (Paris: Le Robert, 1988).

${ }^{9}$ Bernard Dadié, Monsieur Thôgô-gnini (Paris: Présence Africaine, 1970).

10 Bernard Dadié évoque la même idée dans son roman, Un Nègre à Paris, où il écrit: "Avant quand deux Nègres se rencontraient, ils s'arrêtaient, se saluaient, se demandaient les nouvelles des villages, des familles. Maintenant chacun poursuit sa route sans même sourire." Un Nègre à Paris (Paris: Présence Africaine, 1959), pp. 20-21.

11 Beaucoup d'Africanistes ont bien développé cette conception de vie africaine. Voir surtout: John Mbiti, African religions and philosophy (New York: Frederick A. Praeger, Inc., Publishers, 1969), pp. 108-109, 225; Yves Benot, Les indépendances africaines, 2 vols. (Paris: Maspero, 1955), vol. I, p. 56; Jean-Pierre N'Diaye, Elites africaines et culture occidentale: Assimilation ou Résistance (Paris: Présence Africaine, 1969), p. 80; Maurice Delafosse, Les civilisations négro-africaines (Paris: Librairie Stock, 1925), pp. 8-9; Louis-Vincent Thomas, Les idéologies négro-africaines d'aujourd-hui (Dakar:Philosophie et sciences sociales, 1965), p. 30 .

12 Albert Memmi, L'homme dominé (Paris: Gallimard, 1968), p. 27.

Voir aussi notre étude: Ben Jukpor, "Monsieur Thôgô-gnini: une forme particulière de l'individualisme," L'Afrique Littéraire $\mathrm{N}^{\circ} 56$ (1980), pp. 52-59.

13 Bernard Dadié ne manque pas de faire remarquer la nature aliénée de ce tribunal qui se met à imiter servilement le tribunal européen.

14 Jean Pliya, La Secrétaire particulière (Yaoundé: CLE, 1973).

Voir aussi notre étude: Ben Jukpor, "Le problème du comique dans La Secrétaire particulière de Jean Pliya," LittéRéalité Vol. V, No 1 (Printemps 1993), pp. 53-64. 
15 Voir notre étude: Ben Jukpor, "Mhoi-Ceul de Bernard Dadié et les services publics en Afrique," Le Mois en Afrique Nos. 229-230 (1985), pp. 118-129.

16 Frantz Fanon, Peau noire masques blancs (Paris: Editions du Seuil, 1952), p. 48.

17 On se rappelle le complet en jute que les Blancs donnent à Monsieur Thôgô-gnini, pour le caricaturer, en lui disant que c'est le plus beau tissu qui se fait en Europe. Voir B. Dadié Monsieur Thôgô-gnini, op.cit., V, p. 63.

18 Albert Memmi, L’homme dominé, op.cit., p. 19.

19 Bernard Dadié, Béatrice du Congo (Paris: Présence Africaine, 1970).

20 Voir John Mbiti, African religions and philosophy, op.cit., pp. 108-109, 225

21 Jonathan Olumide Lucas, Religions in West Africa and Ancient Egypt (Apapa: Nigerian National Press, 1970), p. 288. Voir aussi: Henri Maurier, Philosophie de l'Afrique noire (Bonn: Anthropos-Institut, 1976), p. 47.

22 Aimé Césare, Et les chiens se taisaient (Paris: Présence Africaine, 1956), p. 68. Voir aussi une autre pièce du même dramaturge: La Tragédie du Roi Christophe (Paris: Présence Africaine, 1970), I, 3, p. 37.

23 Guillaume Oyono-Mbia, Trois prétendants...un mari (London: George G. Harrap \& Co. Ltd., 1971).

${ }^{24}$ La conception de la dot en Afrique diffère ainsi de la signification du terme en Occident où la dot désigne surtout le bien qu'une femme apporte en se mariant.

25 Voir John Mbiti, African religions and philosophy, op.cit., p. 140.

26 Voir: Karl Marx, Economic and Philosophical Manuscripts, traduit par T.B. Bottomore, repris dans Erich Fromm, Marx's concept of Man (New York: Frederick Ungar, 1961), pp. 96103.

${ }^{27}$ Il faut pourtant préciser que ce malentendu ne concerne que le roi du Zaïre. Le malentendu n'existe que chez lui, car pour les Bitandais le langage demeure "clair, précis, rigoureux." 